This approach also allows for mobilization of a full range of treatment strategies, targeting all aspects of pain (physical, psychosocial, functional). To support this approach, the book includes general reviews of pharmacology as well as a review of selected interventional techniques. The latter information is a good general review, but for the pharmacist who is seeking a comprehensive review of the literature regarding medication therapy for persistent pain in older adults, this text falls short. The medication therapies are accurately presented and there is some mention of pharmacokinetic changes that occur in the elderly, but this is done at only a general level. The book does include a general approach to prescribing in older adults, as well as information about the effect of concomitant disease, the World Health Organization pain ladder, and adjuvant treatments.

Where this text distinguishes itself from most other pharmacy texts is in the extensive review of other nonpharmacologic options, including entire chapters on physical therapy and mind-body and energy therapies. The physical therapy section is well written, covering a variety of different approaches and outlining their respective places in therapy. More controversial are the reviews of mind-body and energy therapies. There is an explanation of the theory behind these techniques, and levels of evidence for these strategies are provided. Many patients and some practitioners strongly believe that these strategies are effective, even though it is generally perceived that there is less evidence to support them. The authors suggest that it is important for practitioners to understand these treatments, which their patients may be seeking out. By highlighting the available literature, the authors give readers an opportunity to assess the information and decide the relative merits of the described therapies for themselves.

Managing Pain in the Older Adult is an interesting read that highlights a very good general approach to working with older adults with persistent pain. If read with an analytical eye, it provides information to practitioners looking to enhance their approach to working with older adults suffering from pain.

Allan Mills, PharmD

Department of Pharmacy

Trillium Health Centre

Mississauga, Ontario

\section{Martindale's Drugs Restricted in Sport Pocket Companion, 2008 edition}

Sweetman SC, editor. Pharmaceutical Press, London, UK, 2008. Softcover, 432 pages. ISBN 978085369825 8. Price $£ 19.95$.

According to its editor, Martindale's Drugs Restricted in Sport Pocket Companion, 2008 edition, is "a guide to drugs and medicines that may be restricted in or out of competition in some or all sports, either in their own right, or because they are a derivative of a restricted substance or a member of a prohibited group." The aim of the book is to provide a means for an athlete to determine whether a specific substance is restricted in his or her particular sport.

The book is prefaced with a brief overview of its layout, a disclaimer, a list of abbreviations, and a glossary of terms. The contents are set up alphabetically by drug substance, with the International Nonproprietary Name, where such exists, being used preferentially for each entity. Each monograph is broken down into several sections. Synonyms for each substance are comprehensively listed and extensively indexed in the back of the book for easy reference. There is a separate Cyrillic index. The brief clinical profile that is included with each monograph describes very basic actions and "on-label" therapeutic uses for each substance. The World Anti-Doping Agency (WADA) status and class are listed as well. WADA status refers to whether a drug is prohibited, in or out of competition, and the WADA class refers to the reasoning behind any prohibition.

This reference has been meticulously put together in terms of its comprehensive listing of alternative drug names, and it effectively links that information with the edicts of WADA in terms of prohibited and restricted substances. The multilingual and multinational listings are invaluable, particularly given that athletes' training bases and competition sites span the globe.

The Achilles heel of this book, and any other printed listing of restricted drugs, is that it will be out of date from the moment of publication, since the WADA code is constantly evolving and expanding. Athletes, trainers, coaches, team physicians, and pharmacists cannot assume that consulting a reference such as this one will give them a reliable answer as to whether a substance they may be contemplating taking is restricted for them or not. In particular, one cannot conclude that the absence of a listing for a substance in this publication means that it is not restricted, and even the specific restrictions for substances included in the book may change over time.

For athletes, and for anyone advising athletes, it is reasonable to check Martindale's Drugs Restricted in Sport Pocket Companion as a first step in identifying substances that may result in a positive test. However, without further consultation with national and international sports organizations and their respective doping agencies, such as the Canadian Centre for Ethics in Sport, the Canadian Anti-Doping Program, and WADA, the athlete is at risk of an inadvertent doping violation. For Canadian athletes and their advisors, a visit to the website of the Canadian Centre for Ethics in Sport (http://www.cces.ca) and consultation with their respective sport organizations are both necessary steps when seeking a definitive answer regarding whether a particular substance may result in a doping violation and subsequent sanctioning of the athlete.

Catherine Bond-Mills, BScPhm

London Regional Cancer Program

London Health Sciences Centre

London, Ontario 